\title{
Thermodynamic and detailed kinetic study of the formation of orthophthalaldehyde- agmatine complex by fluorescence intensities
}

Khémesse Kital ${ }^{1,2}$, Moumouny Traoré ${ }^{1,3}$, Diégane Sarr ${ }^{1}$, Moussa Mbaye ${ }^{1}$, Mame Diabou Gaye Seye ${ }^{1}$, Atanasse Coly ${ }^{1}$, François Delattre ${ }^{2}$ and Alphonse Tine ${ }^{1 *}$ (iD

\begin{abstract}
The aim of this work is to determine the thermodynamic parameters and the kinetics of complex formation between orthophthalaldehyde (OPA) and agmatine (AGM) in an alkaline medium ( $\mathrm{pH}$ 13). Firstly, the association constant $\left(K_{a}\right)$ between orthophthalaldehyde and agmatine was determined at different temperatures (between $298 \mathrm{~K}$ and $338 \mathrm{~K}$ ) with a step size of $10 \mathrm{~K}$. Secondly, the thermodynamic parameters such as standard enthalpy $\left(\Delta H^{\circ}\right)$, standard entropy $\left(\Delta S^{\circ}\right)$,and Gibbs energy $(\Delta G)$ were calculated, where a positive value of $\Delta H^{\circ}(+45.50 \mathrm{~kJ} / \mathrm{mol})$ was found, which shows that the reaction is endothermic. In addition, the low value of $\Delta S^{\circ}(+0.24 \mathrm{~kJ} / \mathrm{mol})$ indicates a slight increase in the disorder in the reaction medium. Furthermore, the negative values of $\Delta G$ between $-35.62 \mathrm{~kJ} / \mathrm{mol}$ and $-26.02 \mathrm{~kJ} / \mathrm{mol}$ show that the complex formation process is spontaneous. Finally, the parameters of the kinetics of the reaction between OPA and AGM were determined as follows: when the initial concentration of $A G M\left(5 \times 10^{-6} \mathrm{M}\right)$ is equal to that of the OPA, the results show that the reaction follows an overall 1.5 order kinetics with an initial rate of $5.1 \times$ $10^{-7} \mathrm{Mmin}^{-1}$ and a half-life of $8.12 \mathrm{~min}$. The partial order found in relation to the AGM is 0.8 . This work shows that the excess of OPA accelerates the formation reaction of the complex.
\end{abstract}

Keywords: Agmatine, Orthophthalaldehyde, Kinetics, Thermodynamics, Spectrofluorimetry

\section{Introduction}

Biogenic amines are low molecular weight organic bases (Naila et al. 2010). They can be formed and degraded as a result of normal metabolic activity in animals, plants, and microorganisms (Arena et al. 2001). Indeed, biogenic amines are produced from the free amino acids present in food, either by tissue decarboxylase enzymes or by microbial decarboxylase enzymes (Ladero et al. 2010; Lonvaud-Funel et al. 2001). They can also come from the hydrolysis of nitrogen compounds and the

\footnotetext{
* Correspondence: alphtine@yahoo.fr

'Laboratoire de Photochimie et d'Analyse (LPA), Faculté des Sciences et

Techniques, Université Cheikh Anta Diop, BP 5005, Dakar, Sénégal

Full list of author information is available at the end of the article
}

amination of ketones or aldehydes (Özogul et al. 2019). Thus, these biogenic amines can be produced by microorganisms capable of synthesizing specific decarboxylase enzymes. For example, enterobacteria are mainly producers of putrescine and cadaverine (Suzzi et al. 2003), while enterococci faecia and actobacilli can produce tyramine (Capozzi et al. 2012). Oenococcus oenis are precursors to putrescine, histamine, cadaverine, and spermidine (Marcobal et al. 2004; Guerrini et al. 2002; Landete et al. 2007). The production of these biogenic amines is influenced by the environmental conditions ( $\mathrm{pH}, T$, etc.) favoring the optimal growth of the bacteria, the production of the enzymatic activity (Mazzoli et al. 2009), and the availability of proteins and free amino 
acids (Landete et al. 2006). At low doses, these biogenic amines have important and varied physiological functions. For example, they play an important role as neurotransmitters in vertebrates (Chase and Koelle 2007). Similarly, the most known amine, histamine participates in defense reactions in the body (Fetissov et al. 2000), while putrescine, spermine, and spermidine are involved in the growth, functioning, and proliferation of cells (Ali et al. 2011). That is why, to facilitate the diagnosis of tumors and the follow-up of cancer treatment, measurements of the level of biogenic amine in tumor tissues, blood, and urine are being used more and more (Hougaard et al. 1982). However, at high concentrations, biogenic amines become toxic with very different symptoms according to the biogenic amine (Ladero et al. 2010). For example, histamine can cause headaches, redness, and hypotension, while tyramine induces cerebral bleeding and heart failure (Standarová et al. 2008). In addition, the presence of cadaverine, tyramine putrescine, and agmatine in foods may have a significant synergistic effect with increased histamine levels, causing acute toxicity (Halàz et al. 1994; Shalaby 1996). To recover, the patient can still use medication. However, taking certain drugs such as moclobemide and tranylcypromine (used mainly in the treatment of depression) may inhibit the effect of monoamine oxidase, which is an enzyme that degrades biogenic amines and thus make the toxicity more acute (Onal et al. 2007). Similarly, alcohol is also known among the most active inhibitors against the effects of amine oxidases and therefore increases the risks from these biogenic amines (Gardini et al. 2005). In addition, the degree of deterioration of the food can be measured by the presence of certain biogenic amines: for example, if the presence of tyramine and cadaverine in the food indicates a deteriorated product (Vinci et al. 2002), on the contrary, the presence of agmatine indicates the freshness of the food. Indeed, the presence of agmatine in foods such as meat, fish, and cheese serves as a chemical indicator for their good hygienic qualities (Eldeep et al. 2013). Agmatine is a biogenic polyamine. It was discovered in 1910 by Albrecht Kossel in herring sperm (Kossel et al. 1910). However, it can be synthesized and stored in the astrocytes (Regunathan et al. 1995) and transported to cerebral nerve endings (Goracke-Postle et al. 2007). Also, it can be produced from arginine under the action of the enzyme arginine decarboxylase (ADC) (Sun et al. 2015). It has a wide range of activities related to the functions of the nervous system (Gilad et al. 2000; Dreyfys 1994; Li et al. 1995). Indeed, it acts as a potential neurotransmitter in the brain (Reis and Regunathan, 2000; Halaris and Plietz, 2007). Agmatine is also a regulator of polyamine levels (Isome et al. 2007) and a precursor of putrescine by bacteria action (Alberto et al. 2007; Landette et al. 2008). Thus, the presence of agmatine in the body can generate a lot of interest. In fact, agmatine reduces collagen accumulation in diabetics (Marx et al. 1995), plays a protective role against depression in mice (Mohseni et al. 2017), regulates the growth of epithelial cells for healing wounds (Dreyfys 1994), and increases muscle growth while improving the shape physically. Therefore, agmatine is used as a dietary supplement (Gilad et al. 2014). Finally, agmatine is also used in the treatment of autism spectrum disorders in rats (Kim et al. 2017). Several analytical methods have been used for the quantitative and qualitative determination of agmatine. These methods include high-performance liquid chromatography (HPLC), gas-phase chromatography (GPC), nuclear magnetic resonance (NMR), and spectrofluorimetric method (Custodio et al. 2007; Chen et al. 2010; Mesnard et al. 2000; Nedeljko et al. 2016). Our previous work has been able to quantify the rate of agmatine in some fish products (shrimp) by the spectrofluorimetric method (Kital et al. 2019). Since agmatine is not fluorescent, the OPA has been used as a fluorogenic marker to give a fluorescent OPA - AGM complex. The formation of this complex is dynamic and more or less slow. This complex stabilizes very fastly by agitation or by heating. This is why it is necessary to study the thermodynamic parameters and the kinetics of this reaction and to infer from it the optimal conditions of analysis.

Consumers are currently very demanding about the quality of food, especially fish products. Before any export, these products are subject to strict controls either to quantify toxic products such as histamine and putrescine or to determine their freshness such as agmatine. It is therefore important to determine the level of agmatine in order to have information on the freshness of these products based on the analytical results, which must be done more or less quickly and accurately.

So, the aim of this work is to first determine the thermodynamic parameters of the reaction between OPA and AGM and then to study in detail the formation kinetics of the OPA - AGM complex from the variation of the fluorescence intensities during the formation time of this complex.

The knowledge of these parameters and speed allows us to optimize the time it takes to accurately analyze a sample containing agmatine, especially in the industrial scale where time is very well rated.

\section{Experimental procedures \\ Experimental setup}

Fluorimetric analyses were performed using a Varian Cary Eclipse spectrofluorometer. This spectrofluorometer is coupled with a programmable thermostat for a given temperature. During the experiments, a five-sided polished quartz cell was used (optical path of $1 \mathrm{~cm}$, internal volume of $3.5 \mathrm{~mL}$ ). The fluorescence spectra were 
made by adjusting the voltage to 650 volts and the slot to $5 \mathrm{~nm}$. The weighings were carried out with a Sartorius precision balance sensitive to $0.1 \mathrm{mg}$. The use of pipettes, micropipettes, flasks and beakers, and a Consort brand $\mathrm{C} 6010 \mathrm{pH}$ meter was required for the preparation of the solutions. WinUV softwares for recording fluorescence spectra and OriginPro 8.5 for data processing were also used.

\section{Products}

Agmatine sulfate (97\%), orthophthalaldehyde (97\%), sodium hydroxide $(98 \%)$, and demineralized water were used to this work. All products are analytical grade and were purchased from Sigma-Aldrich.

\section{Methods}

Stock solutions of AGM and OPA, each with a concentration of $10^{-2} \mathrm{M}$, were prepared in $25 \mathrm{~mL}$ vials in an aqueous medium. From each stock solution, we made dilutions to obtain daughter solutions of the desired concentrations. The solutions were protected against light with aluminum foil and stored in a refrigerator. To set the experimental temperature, a minimum waiting time of $3 \mathrm{~min}$ was necessary after placing the solution in the sample holder.

\section{Process to determine thermodynamic parameters}

This section is devoted to the thermodynamic study of the reaction between the OPA and AGM reactants. The reaction process is given by the following equation:

$\mathrm{OPA}+\mathrm{AGM} \rightleftharpoons \mathrm{OPA}-\mathrm{AGM}$ complex $\left[\mathrm{R}_{1}\right]$.

Our previous work has shown that the formation of the complex that arises between the reaction OPA and AGM is a 1:1 ratio in (Kital et al. 2019). Therefore, to determine the association constant $\left(K_{a}\right)$ of the reaction, the Benesi-Hildebrand equation (Padhan et al. 2017; Qin et al. 2014; Rajamohan et al. 2011) was used:

$$
\frac{1}{I_{F}-I_{F \min }}=\frac{1}{I_{F \max }-I_{F \min }}+\frac{1}{\left(I_{F \max }-I_{F \min }\right) K_{a}[\mathrm{OPA}]}
$$

where $K_{a}$ is the complex association constant, $I_{F \min }$ is the initial fluorescence intensity of free AGM, $I_{F}$ is the fluorescence intensity of the OPA - AGM complex, and $I_{F \max }$ the observed fluorescence intensity at the maximum.

From the Benesi-Hildebrand equation, the representation of the function $\frac{1}{I_{F}-I_{F \min }}=f\left(\frac{1}{[\mathrm{OPA}]}\right)$ gives a linear line whose slope and the intercept allow us to calculate association constant $\left(K_{a}\right)$.

In addition, by means of the Van't Hoff equation (Parlayici 2019), we determine the standard enthalpy $\left(\Delta H^{0}\right)$ and the standard entropy $\left(\Delta S^{0}\right)$ given by Eq. 2 .

$$
\ln K_{a}=-\frac{\Delta H^{0}}{R} \cdot \frac{1}{T}+\frac{\Delta S^{0}}{R}
$$

where $R$ is universal gas constant $\left(8.314 \mathrm{~J} \mathrm{~mol}^{-1} K^{-1}\right), T$ is temperature $(K)$, and $K_{a}$ is association constant. The representation of the function $\ln K_{a}=\mathrm{f}\left(\frac{1}{T}\right)$ gives a linear line with slope equal to $-\frac{\Delta H^{0}}{R}$ and intercept to $\frac{\Delta S^{0}}{R}$.

Finally, the standard Gibbs energy $\left(\Delta G^{0}\right)$ is calculated according to the following equation:

$$
\Delta G^{0}=\Delta H^{0}-T \Delta S^{0}
$$

However, Gibbs energy $\Delta G$ will be calculated from the Gibbs relation given by Eq. 4:

$$
\frac{d}{d T}\left(\frac{\Delta G}{T}\right)=-\frac{\Delta H}{T^{2}}
$$

Furthermore, integrating Eq. 4 in the temperature range $T_{0}$ and $T$ at constant $\Delta H$ led to Eq. 5:

$$
\Delta G=\left(1-\frac{T}{T_{0}}\right) \Delta H+\frac{T}{T_{0}} \Delta G^{0}
$$

Therefore, from Eq. 5, the value of the Gibbs energy $(\Delta G)$ can be determined for each temperature value.

\section{Determining the order of a reaction}

To determine the reaction order between OPA and

\begin{tabular}{|c|c|c|c|c|c|}
\hline & OPA & + & AGM & $\rightarrow$ & $\mathrm{OPA}-\mathrm{AGM}\left[\mathrm{R}_{2}\right]$ \\
\hline At $t=0$ & $C_{0}$ & & $C_{0}^{\prime}$ & & 0 \\
\hline At $t \neq 0$ & $C_{0}-x$ & & $C_{0}^{\prime}-x$ & & $x$ \\
\hline
\end{tabular}
AGM, the reaction process between OPA and AGM was determined first. OPA and AGM interact by giving a fluorescent OPA - AGM complex in a 1:1 molar ratio according to the following equation:

where $C_{0}$ and $C_{0}^{\prime}$ represent the initial concentration of [OPA] and [AGM] respectively at the initial instant and $x$ represents the concentration of the complex formed at the instant $t$ which is equal to that of the AGM or the OPA disappeared at this instant $t$.

In this case, the rate $(V)$ of this reaction is written: $V$ $=-\frac{d[\mathrm{OPA}]}{d t}=-\frac{d[\mathrm{AGM}]}{d t}=+\frac{d[\mathrm{OPA}-\mathrm{AGM}]}{d t}$.

This expression can be simplified to the following expression for a reaction that has a rate law as:

$$
V=-\frac{d[\mathrm{AGM}]}{d t}=K[\mathrm{OPA}]^{p}[\mathrm{AGM}]^{q}
$$

where $K$ is the rate constant, $p$ and $q$ are orders of the reaction with respect to OPA and AGM, and the sum $p+q=n$ represents the overall order. 
It is well known that fluorescence intensity $\left(I_{F}\right)$ is proportional to the concentration of the fluorophore (Brown et al. 2013) and proportional to the concentration $x$ of the complex formed. As a result of the above: $I_{F}=2.303 \Phi_{F} I_{0} \varepsilon l x=h x$ where $h=2.303 \Phi_{F} I_{0} \varepsilon l$.

At instant $t \neq 0,[\mathrm{AGM}]=\mathrm{C}=C_{0}-x$. Thus, at the end of the reaction, the fluorescence intensity of the complex becomes maximum corresponding to $C_{0}$. So, one can write that during all the reaction,

$$
[\mathrm{AGM}]=C_{0}\left(\frac{I_{F \max }-I_{F}}{I_{F \max }}\right)
$$

Overall order To determine the overall order, it is more convenient to use equimolar concentrations of OPA and AGM at the initial time. In this case at any time, $[\mathrm{OPA}]=[\mathrm{AGM}]=C_{0}-x=C$.

So, Eq. 6 can be written:

$$
\begin{aligned}
& -\frac{d C}{d t}=K C^{p} C^{q}=K C^{p+q}=K C^{n} \\
& \Leftrightarrow-\frac{d C}{C^{n}}=K d t \Leftrightarrow \int-\frac{d C}{C^{n}}=K \int d t+c t e
\end{aligned}
$$

In these conditions, two possible cases are present: $n \neq$ 1 or $n=1$

\section{- First case $n \neq 1$}

In this case, the solution of Eq. 9 is

$$
\frac{C^{1-n}-C_{0}^{1-n}}{n-1}=K t
$$

$$
\begin{aligned}
& \Leftrightarrow \frac{1}{(n-1) C_{0}^{n-1}}\left(\frac{I_{F \max }}{I_{F} \max -I_{F}}\right)^{n-1}=K t+\frac{1}{(n-1) C_{0}^{n-1}} \\
& \Leftrightarrow \frac{1}{(n-1) C_{0}^{n-1}}\left[\left(\frac{I_{F \max }}{I_{F \max }-I_{F}}\right)^{n-1}-1\right]=K t
\end{aligned}
$$

Finally, the half-life of the reaction is given by

$$
t_{1 / 2}=\frac{C_{0}^{1-n}}{K(n-1)}\left(\frac{1}{2^{1-n}}-1\right)
$$

- Second case $n=1$

In this case, a first order reaction is obtained and the solution of Eq. 9 can be written:

$$
\ln \frac{C_{0}}{C}=K t \Leftrightarrow \ln \left(\frac{I_{F \max }}{I_{F \max }-I_{F}}\right)=K t
$$

where the half-life of the reaction becomes

$$
t_{1 / 2}=\frac{\ln 2}{K} .
$$

Partial orders relative to AGM and OPA To determine the partial order with respect to the AGM for example, one used a large excess of OPA compared to the AGM. When $C_{0}^{\prime} \gg C_{0} \Rightarrow C_{0}^{\prime}-x \approx C_{0}^{\prime}$ at any time. Thus, during the experiment, the concentration of OPA remains constant; in this case, the rate law may be written as

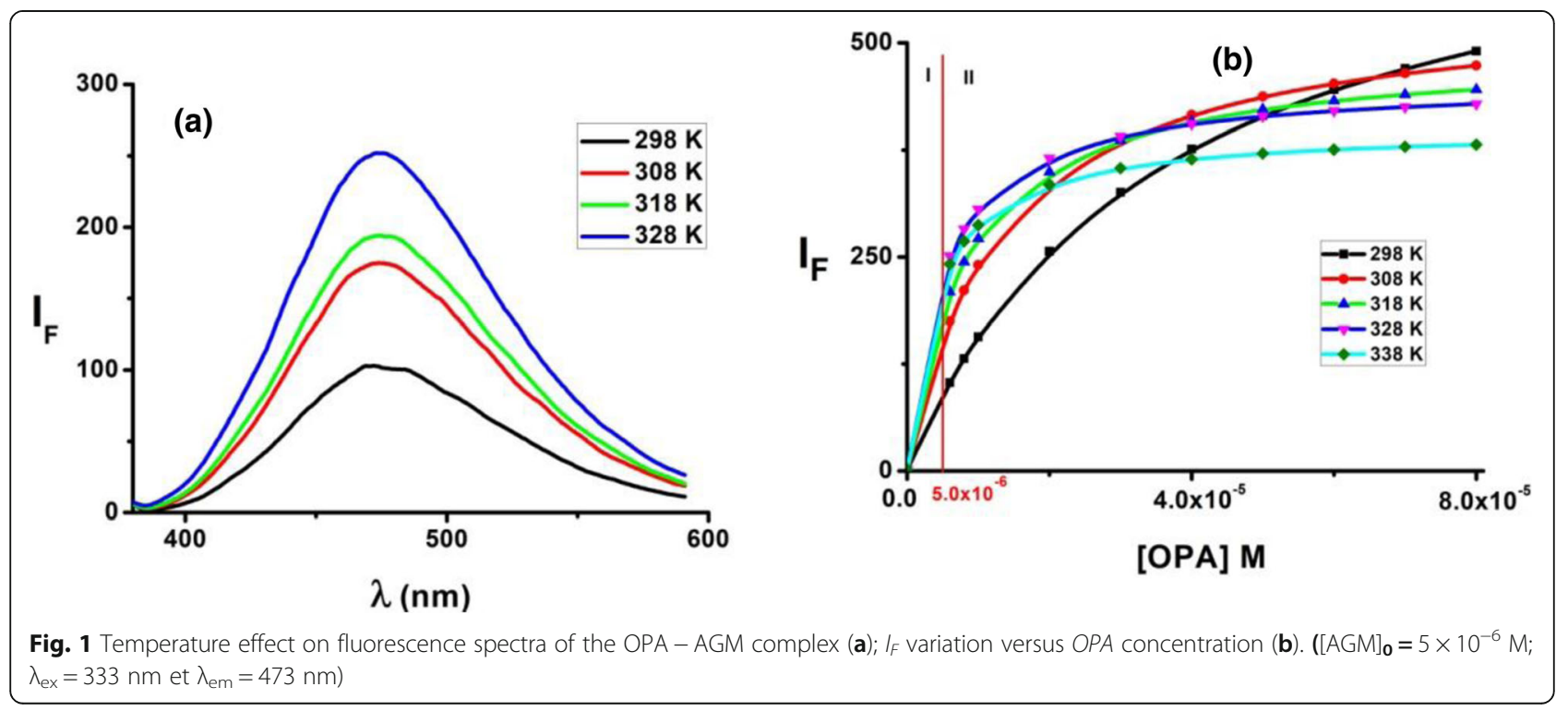




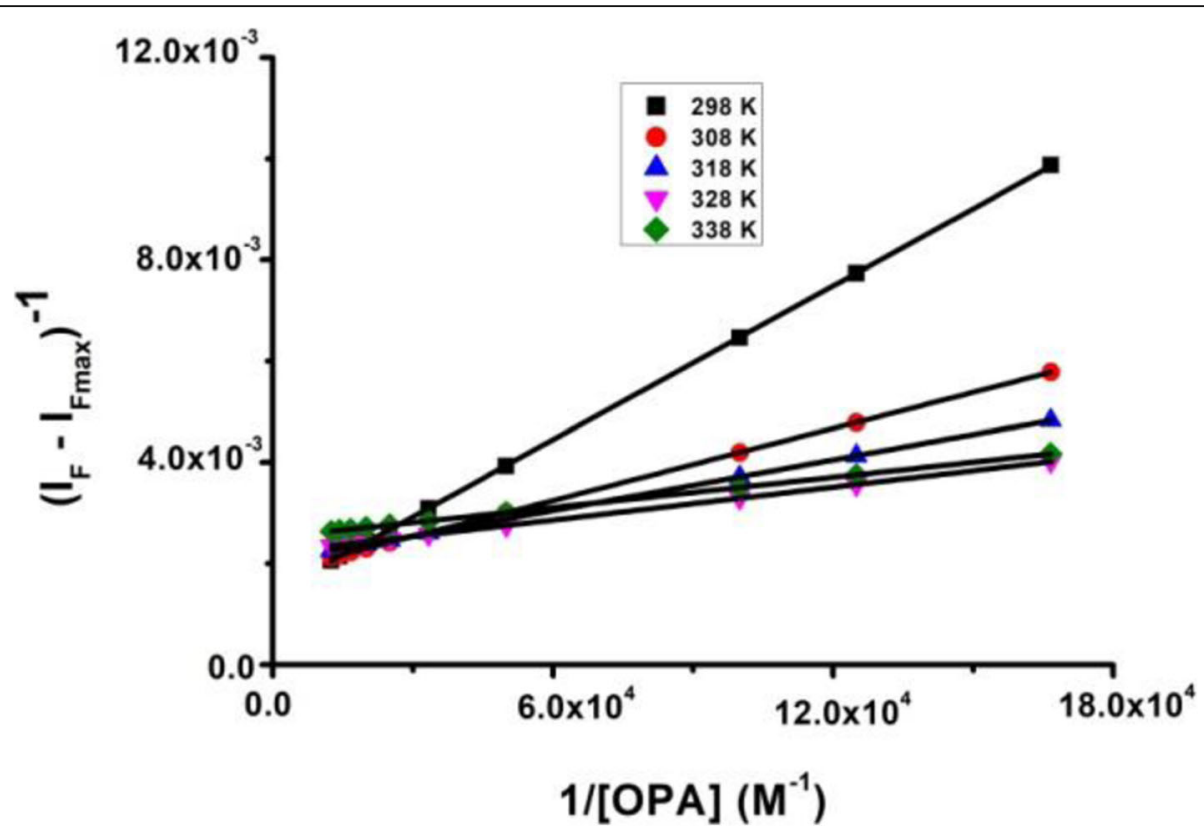

Fig. 2 Benesi-Hildebrand plots from the complexation between the AGM and the OPA

$$
V=K[\mathrm{OPA}]^{p}[\mathrm{AGM}]^{q}=K C_{0}^{\prime p}\left(C_{0}-x\right)^{q}=K^{\prime} C^{q}
$$

where $K^{\prime}=K C_{0}^{\prime p}$ and $K^{\prime}$ is the pseudo-order rate constant with respect to AGM.

Therefore, the expression of the rate law can be simplified as:

$$
V=-\frac{d C}{d t}=K^{\prime} C^{q} \Leftrightarrow \frac{d C}{C^{q}}=-K^{\prime} d t \Leftrightarrow \int-\frac{d C}{C^{q}}=-K^{\prime} \int d t+c t e
$$

In addition, it is also possible to have $q \neq 1$ or $q=1$

\section{Results and discussion}

Thermodynamic parameters

Effects of the temperature and the OPA on the fluorescence spectra of the OPA - AGM complex

To study the effect of OPA on the fluorescence of the complex, the concentration of agmatine was set at
$5 \times 10^{-6} \mathrm{M}$ and the concentration of OPA was varied from $0 \mathrm{M}$ to $8 \times 10^{-6} \mathrm{M}$ for each given temperature. Using the repeat assay method, all measurements were determined successively.

In the temperature range used, emission intensity of the complex increases versus the temperature. However, no change in the shape of the fluorescence spectrum was detected as indicated Fig. 1a. Figure $1 \mathrm{~b}$ represents the variation of the fluorescence intensity $\left(I_{F}\right)$ of the complex versus the concentration of OPA at different temperatures between 298 and $328 \mathrm{~K}$. Figure 1b presents two parts, I and II, where the first part is given by $0<[\mathrm{OPA}] \leq 5 \times 10^{-6} \mathrm{M}$ and corresponding to the formation of the complex which is linear (calibration of the OPA) and the second part starts at $[\mathrm{OPA}]>5 \times 10^{-6} \mathrm{M}$, corresponding to the effect of OPA on fluorescence intensity of the complex (Kital et al. 2019) which is nonlinear. Furthermore, an exaltation of the fluorescence signal of the complex versus

Table 1 Association constant and thermodynamic parameters of the OPA - AGM complex

\begin{tabular}{llllll}
\hline$T(\mathrm{~K})$ & $r^{2}$ & $K_{a}\left(\mathrm{M}^{-1}\right)$ & $\left.\Delta G(\mathrm{~kJ} \mathrm{~mol})^{-1}\right)$ & $\Delta H^{\circ}\left(\mathrm{kJ} \mathrm{mol}{ }^{-1}\right)$ & $\Delta S^{\circ}\left(\mathrm{kJ} \mathrm{K}^{-1} \mathrm{~mol}^{-1}\right)$ \\
\hline 298 & $\mathbf{0 . 9 9 9 9 8}$ & 27,819 & -26.02 & 45.5 & 0.24 \\
308 & 1 & 76,681 & -28.42 & - & - \\
318 & 1 & 122,885 & -30.82 & - & - \\
328 & 1 & 203,743 & -32.35 & - & - \\
338 & 1 & 252,396 & -35.62 & - \\
\hline
\end{tabular}




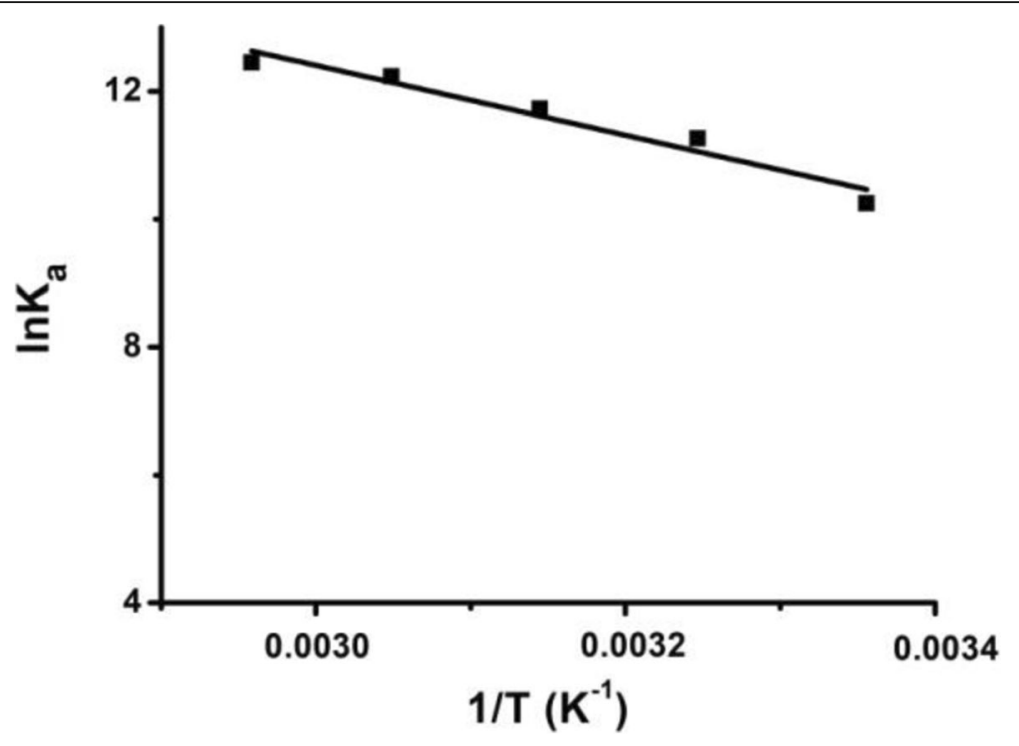

Fig. 3 Van't Hoff plot for the formation of complex

concentration of the OPA is observed in all cases. Beyond $[\mathrm{OPA}]=5 \times 10^{-6} \mathrm{M}$ there is an interaction (hydrogen bonding, charge transfer) between the complex formed and the OPA which more or less enhances the fluorescence of the complex. As the quantity of OPA is increased, a change in the shape of the aggregates is obtained which could influence this excitement. This signal stabilizes from a certain concentration of OPA which corresponds to the optimal concentration $\left([\mathrm{OPA}]_{\max }\right)$. This optimum concentration decreases with increasing temperature. For example, the optimal OPA concentration at $338 \mathrm{~K}$ is much lower than that expected at $298 \mathrm{~K}$ (Fig. 1b).

Determination of association constant $\left(K_{a}\right)$ between OPA and AGM at different temperatures

To determine the correlation of the temperature on the association constant between OPA and AGM at

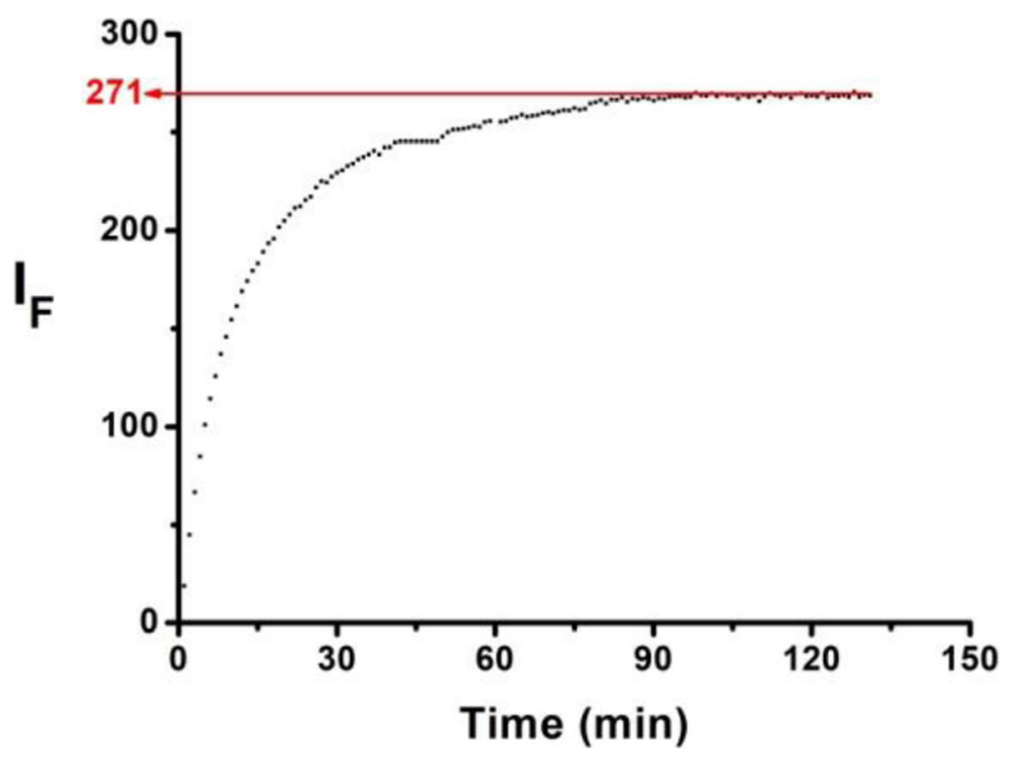

Fig. 4 Plot of fluorescence intensity of the $O P A-A G M$ complex versus time $(t)$. $[A G M]=[O P A]=5 \times 10^{-6} M ; \lambda_{\text {ex }}=333 \mathrm{~nm}, \lambda_{\text {em }}=473 \mathrm{~nm}$ 


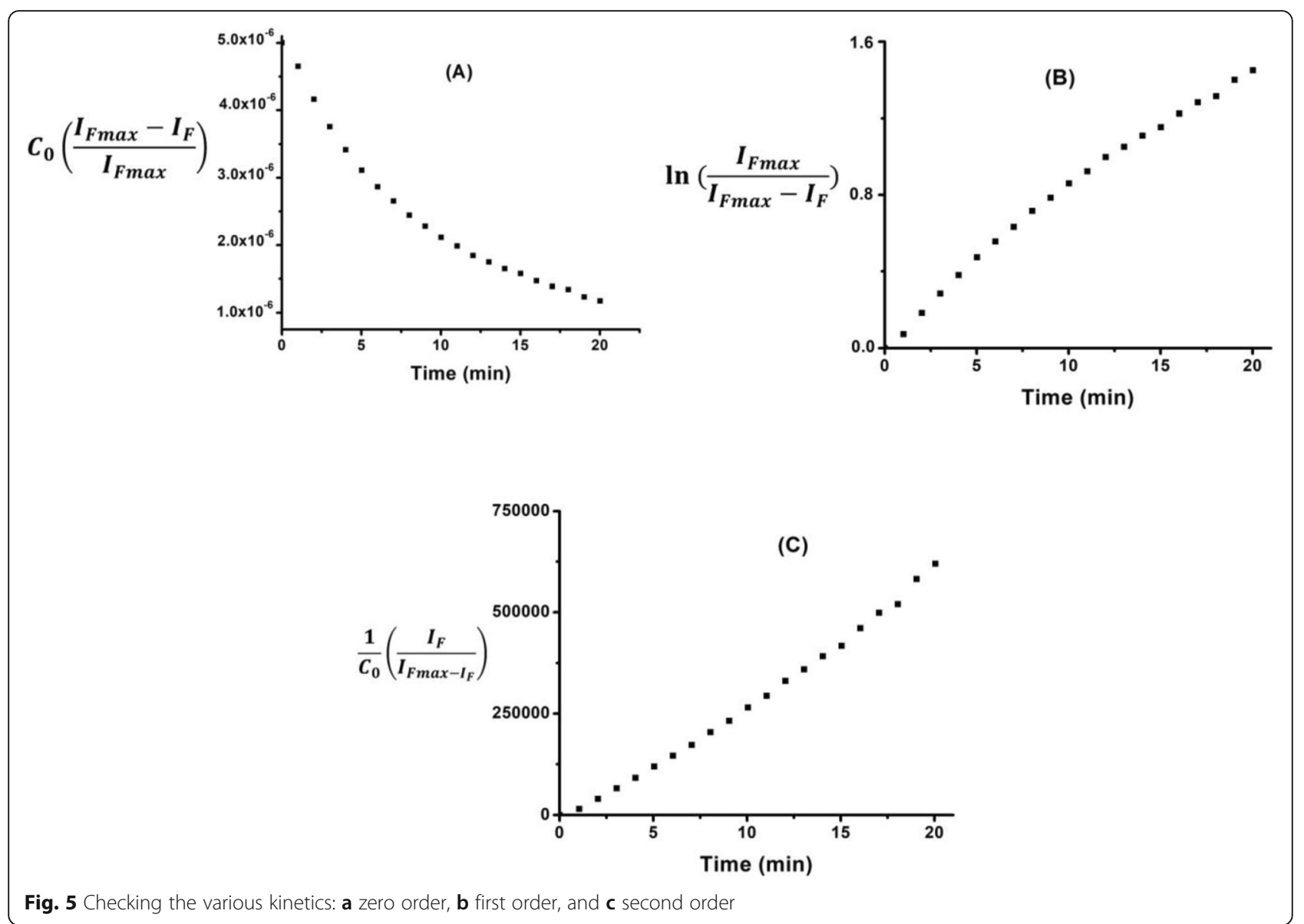

different temperatures, the graphs of Benesi-Hildebrand are plotted in Fig. 2.

Figure 2 shows that linear correlations were observed with correlation coefficients $\left(r^{2}\right)$ greater than 0.9999 which is very close to unity in the temperature range used. This implies a good accuracy of our measurements (Table 1). For each temperature, the association constant $\left(K_{a}\right)$ was determined from the slope and interception. The increase in temperature causes a rise in $K_{a}$. This means that the reaction is favored by an increase in temperature.

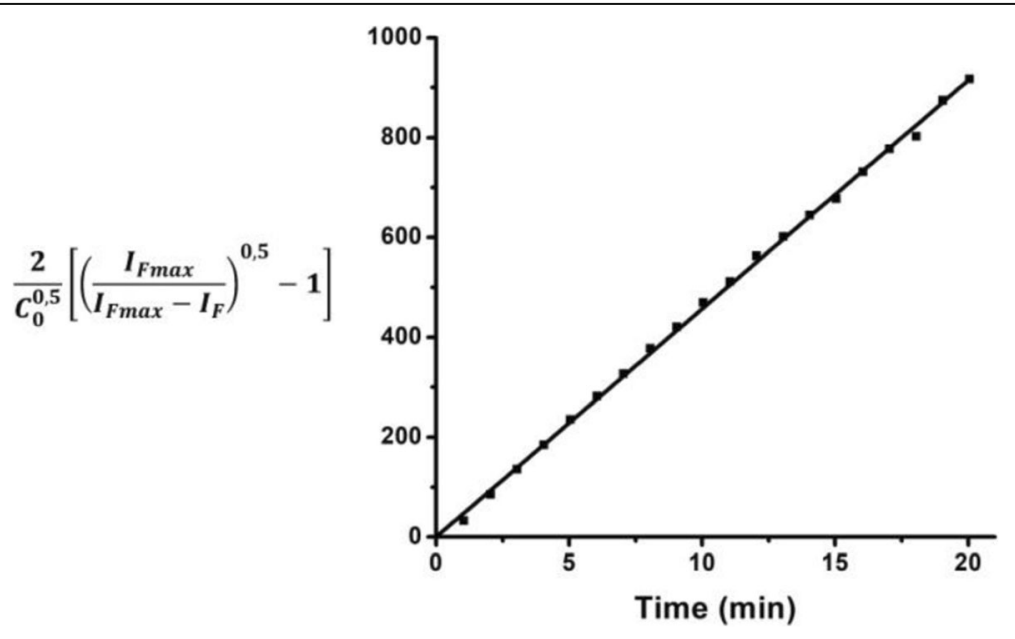

Fig. 6 Checking the kinetics 1.5 order 
Determination of thermodynamic parameters at $298 \mathrm{~K}$

In order to have a better thermodynamic understanding of the complexation reaction between OPA and AGM, the thermodynamic parameters namely the Gibbs free energy $(\Delta G)$, the enthalpy $\left(\Delta H^{\circ}\right)$ and the entropy $\left(\Delta S^{\circ}\right)$ of the reaction were determined. The plot $\ln K_{a}$ versus $1 /$ $T$ (Fig. 3) gives a linear correlation with a coefficient greater than 0.94 (Fig. 3). The intercept and the slope of this straight line allowed us to determine respectively $\Delta S^{\circ}$ and $\Delta H^{\circ}$. However, $\Delta G^{\circ}$ is calculated from Eq. 3. Finally, from Eq. 5, it was possible to calculate $\Delta G$ corresponding to the different temperatures. The overall results are summarized in Table 1.

The negative values of $\Delta G$ show that the process is spontaneous and characterizes the stability of the OPA - AGM complex. On the one hand, these negative values of $\Delta G$ show that the formation of the complex involves electrostatic interactions of the type Van Der WaalsLondon (Dimicoli et al. 1971). On the other hand, the enthalpy $\Delta H^{\circ}$ is positive, which indicates that the reaction is endothermic, thus favored by an increase in temperature. The positive value of entropy $\Delta S^{\circ}$ reflects an increase in system disorder during the formation of the OPA - AGM complex.

\section{Kinetics of formation reaction of the OPA - AGM complex Determination of the overall order}

An equimolar concentration $\left(5 \times \mathbf{1 0}^{-6} \mathrm{M}\right)$ of $O P A$ and $A G M$ was firstly used in order to determine the overall order of the reaction. Then the evolution of fluorescence intensity versus the time $(t)$ was recorded in Fig. 4. Figure 4 shows that the intensity of the fluorescence gradually increases over time before reaching its maximum corresponding to the end of the reaction.

From Fig. 4, it is also possible to determine the general order of the reaction between OPA and AGM. At time $(t)$, the concentration of the complex formed is proportional to the fluorescence intensity $\left(I_{F}\right)$. Thus, the maximum fluorescence intensity $\left(I_{F \max }\right)$ corresponds to the maximum concentration of the complex. With the stoichiometry $(1: 1)$ of the reaction, the concentration of this formed complex is equal to that of the AGM reacted. Furthermore, knowing $I_{F \max }, I_{F}$, and $C_{0}$ (Eq. 7), one can deduce the concentration $C$ of AGM obtained at instant $(t)$. In this work, the order of the reaction $(0$, 1 , and 2 order) was checked first. And Eqs. 11, 14, and 12 are used, respectively.

The representation of the curve $C_{0}\left(\frac{I_{F \max }-I_{F}}{I_{F} \max }\right)=f(t)$ (Eq. 11) gives a shape that is not a straight line (Fig. 5a). Thus, the kinetics of complex formation is not of order 0 . However, this curve resembles either a decreasing exponential or a hyperbola. If it is a decreasing
Table 2 Variation of correlation coefficients according to the order of reaction

\begin{tabular}{ll}
\hline Correlation coefficients $\left(\boldsymbol{r}^{\mathbf{2}}\right)$ & $n$ order of reaction \\
\hline 0.99860 & 1.3 \\
0.99936 & 1.4 \\
$\mathbf{0 . 9 9 9 7 9}$ & $\mathbf{1 . 5}$ \\
0.99972 & 1.6 \\
0.99927 & 1.7 \\
\hline
\end{tabular}

exponential, the kinetics would be of order 1 , but if it is a hyperbola, the kinetics would be of order 2 .

However, the shape of the curve $\ln \left(\frac{I_{F \max }}{I_{F \max }-I_{F}}\right)=f(t)$ (Eq. 14) does not give a straight line, so the kinetics is not of order 1 (Fig. 5b). On the other hand, it can be seen that the curve obtained has a downward concavity.

Similarly, the curve $\frac{1}{C_{0}}\left(\frac{I_{F}}{I_{F} \max -I_{F}}\right)=f(t)$ (Eq. 12) is not a straight line either, so the kinetics are not of order 2 (Fig. $5 \mathrm{c}$ ). The result is a curve with the concavity pointing upwards.

Taking into account the concavities in the shape of Fig. 5b, c, the order of the reaction is between 1 and 2 . For this reason, the order 1.5 was first checked.

Indeed, the curve $\frac{2}{C_{0}^{0.5}}\left[\left(\frac{I_{F \max }}{I_{F \max }-I_{F}}\right)^{0.5}-1\right]=f(t)$ (Eq. 12) gives a positive slope line with a correlation coefficient greater than 0.999 , close to unity (Fig. 6). The slope of this line gives us the value of the speed constant $\mathrm{K}$ which is equal to $47.28 \mathrm{M}^{-\frac{1}{2}} \mathrm{~min}^{-1}$. Thus, we can well note that the kinetics of this reaction is not far from order 1.5.

For greater accuracy, the case where the $\mathrm{n}$ order would be $1.3,1.4,1.6$, and 1.7 was verified, respectively. In all cases, straight lines were obtained with a positive slope and correlation coefficients close to unity (Table 2). However, this table shows that the correlation coefficient

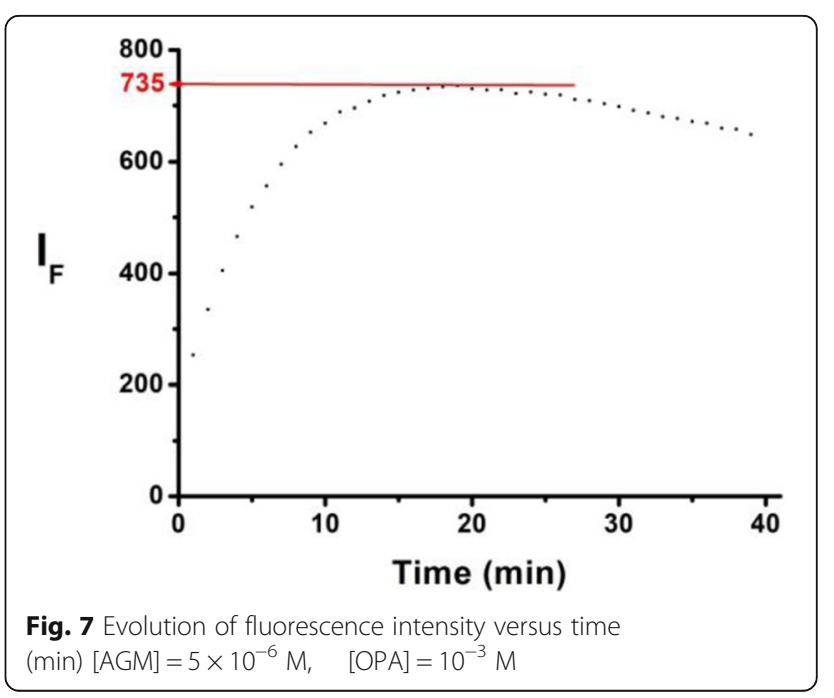




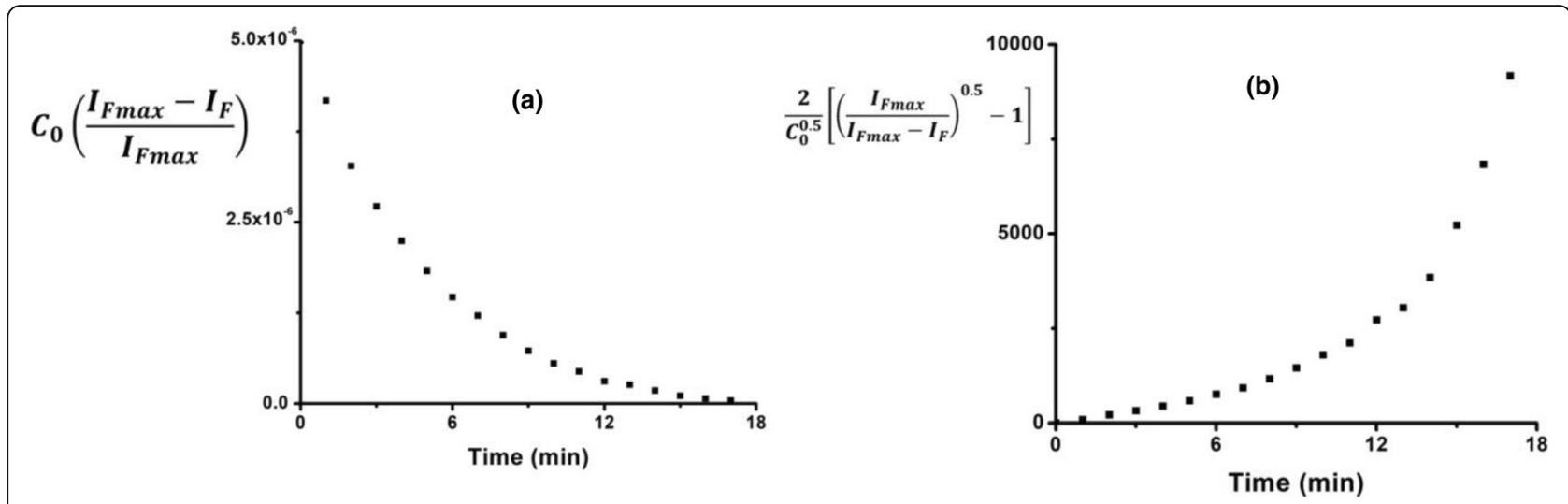

Fig. 8 Verification of the reaction orders: 0 order (a) and 1.5 order (b)

corresponding to 1.5 order is closer to unity. In addition, these coefficients move away from the unit as the estimated value of $\mathrm{n}$ deviates from 1.5. For all these reasons, it can be concluded that the association reaction between the OPA and the AGM is 1.5 overall order.

\section{Determination of reaction orders with respect to AGM and OPA}

To determine the partial order with respect to AGM $\left(5 \times 10^{-6} \mathrm{M}\right)$, a large excess of OPA $\left(10^{-3} \mathrm{M}\right)$ was used. The evolution of the fluorescence intensity of the OPA - AGM complex versus time $(t)$ is shown in Fig. 7. It is noted that the fluorescence intensity increases with respect to $t$ until it reaches a maximum $\left(t_{\max }=20 \mathrm{~min}\right)$ before decreasing afterwards.

Therefore, according to Eq. 16, it follows that:
$V=K C_{0}^{\prime p} C^{q}=K^{\prime} C^{q}$ with $C_{0}^{\prime}=10^{-3} \mathrm{M}=[\mathrm{OPA}], C=$ $C_{0}-x=[\mathrm{AGM}]_{t}$, and $K^{\prime}=K C_{0}^{\prime p}$

where $K$ is the pseudo-order rate constant with respect to AGM.

In addition, it is also known that the overall order $(n)$ of the reaction is equal to 1.5 , which implies that the $q$ order with respect to agmatine is between 0 and 1.5 because $n=p+q$.

We will therefore start by checking the extreme cases: first case $q=0$ and second $q=1.5$ before checking the intermediate orders.

If $q=0$, experience shows that the curve $C_{0}\left(\frac{I_{F \max }-I_{F}}{I_{F} \max }\right)$ $=f(t)$ is not a straight line (Fig. 8a). It looks more like a decreasing exponential or a hyperbola. However, it could not be a hyperbola because the global order is equal to 1.5. If it is a decreasing exponential, the partial order

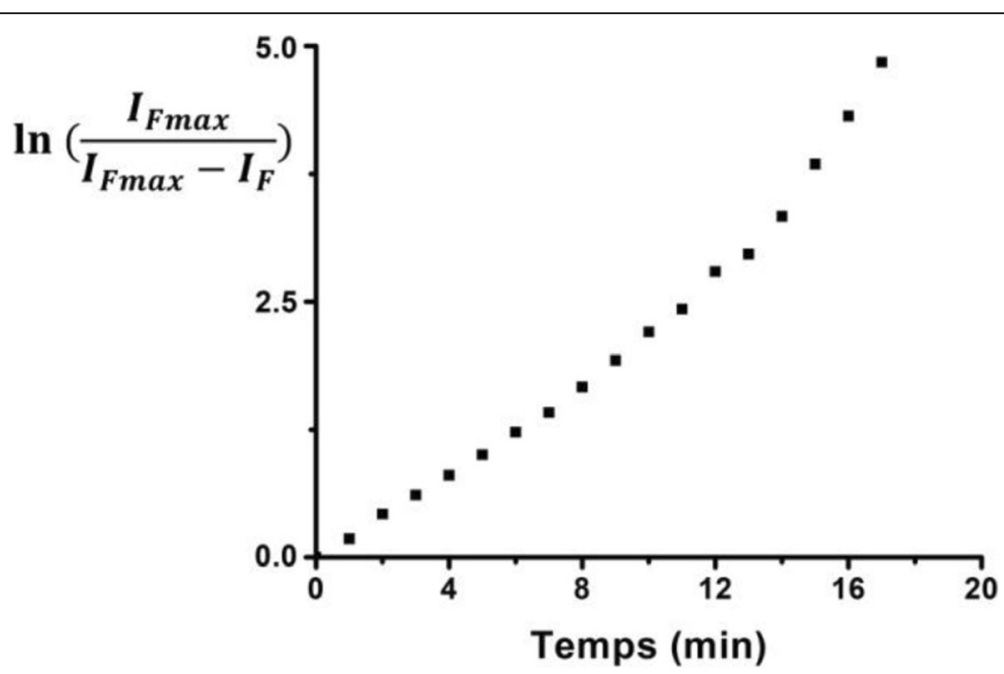

Fig. 9 Verification of the first order 


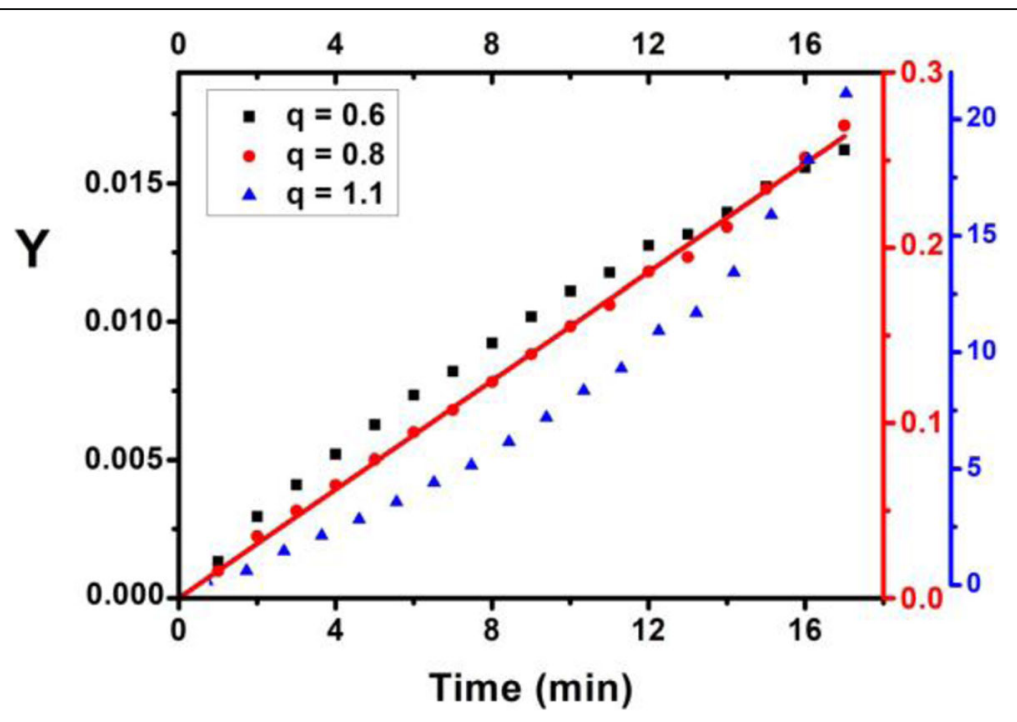

Fig. 10 Verification of the different orders $q$ between 0.6 and 1.1. $q=1: Y=\ln \left(\frac{I_{F} \max }{I_{F} \max }-I_{F}\right), q \neq 1: Y=\frac{1}{(q-1) C_{0}^{q-T}}\left[\left(\frac{I_{F} \max }{I_{F} \max }-I_{F}\right)^{q-1}-1\right]$

with respect to the AGM is equal to 1 , which is still to be verified.

If $q=1.5$, according to Eq. 12 , the curve $\frac{2}{C_{0}^{0.5}}[$ $\left.\left(\frac{I_{F \max }}{I_{F \max }-I_{F}}\right)^{0.5}-1\right]=f(t)$ represented by Fig. 9b should give a line of slope $K$. Experience shows that the curve does not show a straight line (Fig. 8b). This indicates that the kinetics are not of order 1.5 with respect to the AGM.

Thus, this kinetics is neither 0 order and nor 1.5 order. Since Fig. 8a looks like a decreasing exponential, it is judicious to check if the reaction is a first order with respect to AGM.

For instance, if the reaction is the first order, according to Eq. 14, the plot $\ln \left(\frac{I_{F \max }}{I_{F \max }-I_{F}}\right)=f(t)$ shown in Fig. 9 should give a straight line with slope $K^{\prime}$. However, experience shows that there is not a straight line and the plot obtained has a concavity oriented upwards. Thus, it would be more judicious to check the orders lower than 1.

Figure 10 shows the plots representing the different orders studied (between 0.6 and 1.1). As observed, all

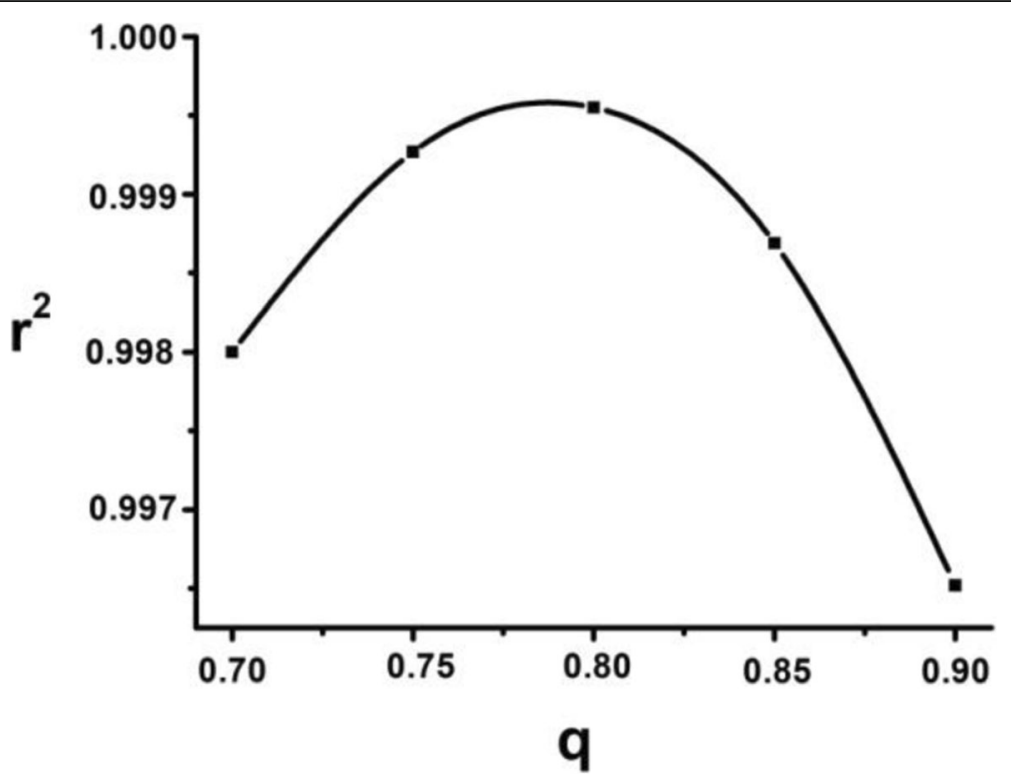

Fig. 11 Variation of the correlation coefficient versus to the order of reaction 
Table 3 Parametric results of formation kinetics of the OPA - AGM complex

\begin{tabular}{lllll}
\hline$C_{r}$ & Order & $r^{2}$ & $V_{0}\left(\mathrm{M} \mathrm{min}^{-1}\right)$ & $t_{1 / 2}(\mathrm{~min})$ \\
\hline$[\mathrm{OPA}]=[\mathrm{AGM}]=5 \times 10^{-6} \mathrm{M}$ & $1.5^{\mathrm{a}}$ & 0.9998 & $5.1 \times 10^{-7}$ & 8.12 \\
{$[\mathrm{AGM}]=5 \times 10^{-6} \mathrm{M} ;[\mathrm{OPA}]=10^{-3} \mathrm{M}$} & $0.8^{\mathbf{b}}$ & 0.9996 & $8.9 \times 10^{-7}$ & 3.6 \\
\hline
\end{tabular}

$C_{r}$ concentration of reactants, $V_{0}$ rate at the initial concentration of the AGM and OPA

${ }^{a}$ Overall order of reaction

${ }^{\mathrm{b}}$ Order with respect to AGM

these different plots have a concavity directed either up or down, except that of the order 0.8 which is linear. This proves that the order with respect to the AGM is close to 0.8 .

To determine accurately the value of $q$, the cases where $q$ is equal to $0.7,0.75,0.8,0.85$, and 0.9 have been checked, respectively. For these values of $q$, a linear correlation occurred with correlation coefficients $\left(r^{2}\right)$ between 0.9965 and 0.9996 . The representation of the plot $r^{2}$ versus $q$ order admits a maximum at the point $\left(r^{2}\right.$ greater than 0.999 and $q$ substantially equal to 0.8$)$. In addition, the values of these correlation coefficients decrease on both sides away from the value 0.8 (Fig. 11). Thus, it can be concluded with accuracy that the order with respect to agmatine is equal to 0.8 .

Thus, the reaction has an overall 1.5 order and 0.8 order with respect to $A G M$. Therefore, the order with respect to the OPA would be equal to 0.7.

Moreover, from rate constants, the different initial rates of reaction $\left(V_{0}\right)$ were determined and half-life $\left(t_{1 / 2}\right)$ for the two cases by using Eqs. 6 and 13, respectively. Thus, for the overall 1.5 order, $V_{0}=5.1 \times 10^{-7} \mathrm{M} \mathrm{min}^{-1}$ and $t_{1 / 2}=8.12 \mathrm{~min}$. In the case where the excess OPA was used, $V_{0}=8.9 \times 10^{-7} \mathrm{M} \mathrm{min}^{-1}$ and $t_{1 / 2}=3.6 \mathrm{~min}$. The results are summarized together in Table 3 .

Table 3 shows that the initial rate $\left(V_{0}\right)$ of the reaction between the OPA and the AGM is higher when the OPA is in excess. In parallel, the half-life $\left(t_{1 / 2}\right)$ obtained with an excess of OPA is much lower. Thus, the excess of OPA accelerates the reaction between the OPA and the AGM.

This large amount of OPA used is of great importance. Indeed, during the industrial analysis of agmatine in different matrices such as fish products, fruits, wine, and physiological fluids, time plays an important role. It is therefore advisable to work with a high concentration of OPA to accelerate complexation reaction in a relatively short time. In addition, to avoid interference effects with other amines, it is necessary to use a large excess of OPA.

\section{Conclusion}

In this work, the first the thermodynamic parameters were studied, and then the kinetics of the reaction of formation of the OPA - AGM complex was studied in an exhaustive manner. The thermodynamic study shows that the association constants between OPA and AGM increase remarkably when the temperature is raised. The positive value of the enthalpy $\left(\Delta H^{\circ}\right)$ shows that the reaction is endothermic and therefore favored by an increase in temperature. Similarly, the positive value of the entropy $\left(\Delta S^{\circ}\right)$ found explains the existence of a growing disorder during the reaction. However, the negative value of free energy $(\Delta G)$ shows that the reaction between OPA and AGM is spontaneous. These results show that the analysis of agmatine by the fluorimetric method can be done at room temperature and does not require a large amount of energy. Moreover, as the reaction between OPA and AGM is endothermic and spontaneous, in tropical (hot) countries, the analysis can be done directly at room temperature, without the use of heating compared to cold countries.

The kinetics of the reaction of complex formation between the OPA and the AGM admits an overall 1.5 order and 0.8 order with respect to the AGM. Similarly, this study shows that the initial rate of the reaction increases with the concentration of OPA and in parallel, the half-life decreases in the opposite direction of this concentration: this shows that the excess OPA accelerates the reaction. In addition, the excess OPA increases the fluorescence intensity of the complex. This excess also increases the speed of formation of the OPA AGM complex while reducing its optimal formation time. The reduction of this time reveals a capital importance in analysis, especially in industrial analysis, because it saves time and money.

Thus, this work shows that the ideal conditions for the determination of agmatine in several ranges of matrices (e.g., industrial analysis) are to work with an excess of OPA without the need to cool the cell. This study can therefore contribute to the industrial analysis of agmatine in various matrices: fish, shrimps, and fruits.

\section{Abbreviations}

AGM: Agmatine; OPA: Orthophthalaldehyde; OPA-AGM: Complex between orthophthalaldehyde and agmatine; ADC: Arginine decarboxylase; max: Maximal

\section{Acknowledgements}

This work was financially supported by the "Service de Coopération et d'Action Culturelle (SCAC)," the French Embassy in Dakar, Senegal, for a French Cooperation Ph.D. grant (2015 Program) in support of this work. 


\section{Authors' contributions}

This study was designed by AT. The experimental work was performed by $K K, M T, D S$, and MB. AT, FD, AC, and MDGS drafted the manuscript and interpreted the data. All authors read and approved the final manuscript.

\section{Funding}

French Cooperation Ph.D. grant (2015 Program)

\section{Availability of data and materials}

Research data have been provided in the manuscript.

\section{Competing interests}

Not applicable.

\section{Author details}

'Laboratoire de Photochimie et d'Analyse (LPA), Faculté des Sciences et Techniques, Université Cheikh Anta Diop, BP 5005, Dakar, Sénégal. 'Laboratoire de Synthèse Organique et Environnement, EA2599, Université du Littoral Côte d'Opale, 145 avenue Maurice Schumann, BP 59140, Dunkerque, France. ${ }^{3}$ Université Peleforo Gon Coulibaly, BP 1328, Korhogo, Côte d'Ivoire.

Received: 19 February 2020 Accepted: 13 August 2020

Published online: 10 September 2020

\section{References}

Alberto MR, Arena ME, De Nadra MCM. Putrescine production from agmatine by lactobacillus hilgardii: effet of phenolic compounds. J. Food Control. 2007;18: 898-903.

Ali MA. Poortvliet E, Strömberg R, Yngve. Polyamines in foods: development of a food database. Food \& Nutr. Res. 2011;55:1-15.

Arena ME. Manca de Nadra MC. Biogenic amine production by Lactobacillus. J. Appl. Microbiol. 2001;90:158-62.

Brown SC, Poujol C. Mieux comprendre les fluorochromes pour la microscopie. La CNRS Formation : la Microscopie Confocale. 2013:1-37.

Capozzi V, Russo P, Ladero V, Fernández M, Fiocco D, Alvarez MA, Grieco F, Spano G. Biogenic amines degradation by Lactobacillus plantarum: toward a potential application in wine. Front. Microbiol. 2012;3:1-6.

Chase DL, Koelle MR. Biogenic amine neurotransmitters in C. elegans, WormBook, (Eds). The C. elegans Research Community, 2007; 1-15.

Chen GG, Turecki G, Mamer OA. A novel liquid-liquid extraction and stable isotope dilution $\mathrm{NCl}-\mathrm{GC}-\mathrm{MS}$ method for quantitation of agmatine in postmortem brain cortex. J. Mass. Spectrom. 2010;45:560-5.

Custodio FC, Tavares E, Gloria MBA. Extraction of bioactive amines from grated parmesan cheese using acid, alkaline and organic solvents? J. Food compos. Anal. 2007;20:280-8.

Dimicoli J-L, Héléne G. Interactions entre acides aminés et acide nucléiques. IIIétude par absorption et résonance magnétique nucléaire de la formation de complexes entre le tryptophane et les constituants des acides nucléique. J. Biochimie. 1971:53:331-45.

Dreyfys JC. L'agmatine, un nouveau neurotransmetteur? J. Medec./sci. 1994 ; 10 : 589.

Eldeep GSS, Mokhtar SM, Mostafa GA, Taha RA, Gaballa AA. Relationship between Biogenic Amine Content and Hygienic Quality of Raw Meet in Fresh Fermented Sausage. J. Food Nutr Disor. 2013:2:1-7.

Fetissov SO, Meguid MM, Chen C, Miyata G. synchronized release of dopamine and serotonin in the medial and lateral hypothalamus of rats, Neurosc. 2000; 101: 657-663

Gardini F, Zaccarelli A, Belletti N, Faustini F, Cavazza A, Martuscelli M, Mastrocola $D$, Suzzi G. Factors influencing biogenic amine production by a strain of Oenococcus oeni in a model system. J. Food Control. 2005;16:609-16.

Gilad GM, Gilad VH. Agmatine, and polyaminoguanidine-bound heterocyclic compounds for neurtrauma and neurodegenerative diseases. United States Patent. 2000;6114392:1-8.

Gilad GM, Gilad VH. Long-term (5 years), high daily dosage of dietary agmatineevidence of safety: a case report. J. Med. food. 2014;17:1256-9.

Goracke-Postle CJ, Overland AC, Stone LS, Fairbanks CA. Agmatine transport into spinal nerve terminals is modulated by polyamine analogs. J. Neurochem. 2007;100:132-41

Halaris A Plietz JJ. Agmatine Methabolic Pathwaye and spectrum of Activity in Brain. J. CNS Drugs. 2007;21:885-900.
Halàz A, Baràth A, Simon-Sarkadi L, Holzapfel W. Biogenic amines and their production by microorganisms in food. J. Trends Food Sci. Technol. 1994:5:42-8.

Hougaard DM, Larsson LI. Polyamine cytochemistry, Use of a novel o-phtalaldehyde method for visualizing spermidine and spermine. Comparisons to the formaldehyde-fluorescamine method J. Histochem. 1982;76:247-59.

Isome M, Lortie MJ, Murakami Y, Parisi E, Matsufuji S, Satriano J. The antiproliferative effects of agmatine correlate with the rate of cellular proliferation. J. Am. Physiol. Cell. Physiol. 2007;293:705-11.

Kim J-W, Seung H, Kim KC, Gonzales ELT, Oh HA, Yang SM, Ko MJ, Han S-H, Banerjee S, Shin CY. Agmatine rescues autistic behaviors in the valproic acidinduced animal model of autism. Neuropharm. Part A. 2017;113:71-81.

Kital K, Traoré M, Sarr D, Mbaye M, Mbaye O, Cisse L, Seye MDG, Coly A, Delattre $\mathrm{F}$, Tine A. Determination of agmatine rate by spectrofluorimetric method in alkaline medium: optimization and application on shrimp. J. Chem. Biochem. 2019;7:15-26.

Kossel A. Üsber das agmatine. Zeitschrift fur Physiologische Chemie. 1910:257-61.

Ladero V, Calles-Enríquez M, Fernández M, Alvarez MA. Toxicological effects of dietary biogenic amines. Current Nutr. \& Food Sci. 2010;6:145-56.

Landete JM, Ferrer S, Pardo I. Biogenic amine production by lactic acid bacteria, acetic bacteria and yeast isolated from wine. Food Control. 2007;18:1569-74.

Landete JM, Pardo I, Ferrer S. Histamine, histidine, and growth-phase mediated regulation of the histidine decarboxylase gene in lactic acid bacteria isolated from wine. FEMS Microbiol. Lett. 2006;260:84-90.

Landette JM, Arena ME, Pardo I, De Nadra MCM, Ferrer S. Comparative survey of putrescine production from agmatine deamination in different bacteria. J. Food Microbiol. 2008;25:882-7.

Li G, Regunathan S, Reis DJ. Agmatine is synthesized by a mitochondrial arginine decarboxylase in rat brain. Ann NY Acad of Sci. 1995:763:325-9.

Lonvaud-Funel A. Biogenic amines in wines: role of lactic acid bacteria. Microbiol. Lett. 2001:199:9-13.

Marcobal A. de las Rivas B, Moreno-Arribas MV, Munoz R. Identification of the ornithine decarboxylase gene in the putrescine-producer Oenococcus oeni BIFI-83. FEMS Microbiol. Lett. 2004;239:213-20.

Marx M, Trittenwein G, Aufrich C, Hoeger H, Lubec B. Agmatine and spercmidine reduce collagen accumulation in kidneys of diabetic $\mathrm{db} / \mathrm{db}$ mice. J. Nephron. 1995:65:155-8.

Mazzoli R, Lamberti C, Coisson JD, Purrotti M, Arlorio M, Giuffrida MG, Giunta C, Pessione E. Influence of ethanol, malate and arginine on histamine production of Lactobacillus hilgardii isolated from an Italian red wine. Amino Acids 2009; 36: 81-89.

Mesnard F, Azaroual N, Marty D, Fliniaux M-A, Robins RJ, Vermeersch G, Monti J$P$. Use of $15 \mathrm{~N}$ reverse gradient two-dimensional nuclear magnetic resonance spectroscopy to follow metabolic activity in Nicotiana plumbaginifolia cellsuspension cultures. J. Planta. 2000;210:446-53.

Mohseni G, Ostadhadi S, Imran-Khan M, Norouzi-Javidan A, Zolfaghari S, Haddadi $\mathrm{N}-\mathrm{S}$, Dehpour A-R. Agmatine enhances the antidepressant-like effect of lithium in mouse forced swimming test through NMDA pathway. J. Biomed. Pharmacother. 2017:88:931-8.

Naila A, Flint S, Fletcher G, Bremer P, Meerdink G. Control of biogenic amines in food - Existing and emerging approaches. J. Food Sci. 2010;751:39-150.

Nedeljko P, Turel M, Kosak A, Lobnik A. Synthesis of hybrid thiol-functionalized $\mathrm{SiO} 2$ particles used for agmatine determination. J. Sol-Gel Sc. Technol. 2016; 79:487-96

Onal A. A review analytical methods for the determination of biogenic amines in foods. J. Food chem. 2007;103:1475-86.

Özogul Y, Özogul F. Biogenic amines in food: analysis, occurrence and toxicity. Royal soc. Chem. 2019:1-13.

Padhan P, Sethy A, Behera PK. Host-Guest interaction between Ofloxacin- $\beta$ Cyclodextrin complexes in acidic and neutral pH: A fluorescence quenching study. J. Photochemistry and Photobiology A: Chem. 2017;337:165-71.

Parlayici Ş. Alginate-coated perlite beads for the efficient removal of methylene blue malachite green, and methyl violet from aqueous solutions: kinetic, thermodynamic, and equilibrium studies. J. Anal. Sc. and Technol. 2019;10:1-15.

Qin J-C, Li T-R, Wang B-D, Yang Z-Y, Fan L. Fluorescent sensor for selective detection of $\mathrm{Al} 3+$ based on quinoline-coumarin conjugate. J. Spectrochim. Acta Part A. 2014;133:38-43.

Rajamohan R, Swaminathan M. Effect of inclusion complexation on the photophysical behavior of diphenylamine in $\beta$-cyclodextrin medium: a study by electronic spectra. J. Spectrochim. Acta Part A. 2011:83:207-12.

Regunathan S, Feinstein DL, Raasch W, Reis DJ. Agmatine (decarboxylated arginine) is synthesized and stored in astrocytes. J. Neuroreport. 1995;6:1897900 
Reis DJ, Regunathan S. Is agmatine a novel neurotransmitter in Brain? Trends Pharmacol. Sci. 2000;21:187-93.

Shalaby AR. Significance of biogenic amines to food safetyand human health. J. Food Res. Intern. 1996;29:675-90.

Standarová E, Borkovcová I, Vorlová L. The occurrence of biogenic amines in dairy products on the czech market. J. Acta Sci. Pol. Medicina Veterinaria. 2008;7:35-42.

Sun $X$, Song W, Liu L. Enzymatic production of agmatine by recombinant arginine decarboxylase. J. Molecular Catalysis B: Enzymatic. 2015;121:1-8.

Suzzi G, Gardini F. Biogenic amines in dry fermented sausages: a review. Int. J. Food Microbiol. 2003:88:41-54

Vinci G, Antonelli ML. Biogenic amines: quality index of freshness in red and white meat. J. Food Control. 2002;13:519-24.

\section{Publisher's Note}

Springer Nature remains neutral with regard to jurisdictional claims in published maps and institutional affiliations.

\section{Submit your manuscript to a SpringerOpen ${ }^{\odot}$ journal and benefit from:}

- Convenient online submission

- Rigorous peer review

- Open access: articles freely available online

- High visibility within the field

- Retaining the copyright to your article

Submit your next manuscript at $\boldsymbol{\nabla}$ springeropen.com 